\title{
The influence of carbon morphologies and concentrations on the rheology and electrical performance of screen-printed carbon pastes
}

\author{
Sarah-Jane Potts ${ }^{1, *}$ (D), Tatyana Korochkina ${ }^{2}$ (D), Alex Holder $^{2}$ (D), Eifion Jewell ${ }^{1}$ (D), \\ Chris Phillips ${ }^{2}$ (1), and Tim Claypole ${ }^{2}$ (1) \\ ${ }^{1}$ SPECIFIC, College of Engineering, Swansea University, Bay Campus, Crymlyn Burrows, Swansea SA1 8EN, UK \\ ${ }^{2}$ Welsh Centre for Printing and Coating, College of Engineering, Swansea University, Bay Campus, Crymlyn Burrows, \\ Swansea SA1 8EN, UK
}

Received: 1 July 2021

Accepted: 8 November 2021

Published online:

3 January 2022

(C) The Author(s) 2021

\begin{abstract}
Screen-printing inks containing various morphologies of carbon are used in the production of a variety of printed electronics applications. Particle morphology influences the rheology of the ink which will affect the deposition and therefore the electrical performance of a printed component. To assess the effect of both carbon morphology and concentration on print topography and conductivity, screen printable carbon inks with differing loading concentrations of graphite, carbon black and graphite nanoplatelets (GNPs) were formulated, printed and characterised, with rheological and novel print visualisation techniques used to elucidate the mechanisms responsible. Carbon morphology had significant effects on the packing of particles. The smaller carbon black particles had more interparticle interactions leading to better conductivities, but also higher ink viscosities and elasticities than the other morphologies. Increases in carbon concentration led to increases in film thickness and roughness for all morphologies. However, beyond a critical point further increases in carbon concentration led to agglomerations of particles, mesh marking and increases in surface roughness, preventing further improvements in the print conductivity. The optimal loading concentrations were identifiable using a custom-made screen-printing apparatus used with high speed imaging for all morphologies. Notable increases in filamentation during ink separation were found to occur with further increases in carbon concentration beyond the optimum. As this point could not be identified using shear rheology alone, this method combined with shear rheology could be used to optimise the carbon concentration of
\end{abstract}

Handling Editor: Annela M. Seddon.

Address correspondence to E-mail: Sarah-Jane.Potts@swansea.ac.uk

E-mail Addresses: T.V.Korochkina@Swansea.ac.uk; A.Holder@swansea.ac.uk; E.Jewell@Swansea.ac.uk;

C.O.Phillips@swansea.ac.uk; T.C.Claypole@swansea.ac.uk 
screen-printing inks, preventing the use of excess material which has no benefit on print quality and conductivity.

\section{Introduction}

Screen-printed carbon inks and pastes are widely used in the manufacture of a range of printed electronics applications due to their electrical conductivity and relatively low cost. These include resistive heaters [1, 2], electrochemical sensors [3], printed batteries [4], Perovskite PV [5, 6], as well as energy harvesting in the form of printed pyroelectrics [7] and thermoelectrics [8]. These inks typically consist of a range of carbon morphologies to tailor the performance and cost of the inks.

Graphite (G), carbon black (CB) and graphite nanoplatelets (GNPs) are among the most common forms of carbon used in a large proportion of these devices in industry. This is due to their ease of use and economic advantage over other commercial conductive materials, such as silver and more recent derivatives of carbon such as graphene and carbon nanotubes (CNTs).

Graphite is a multi-layered planar crystalline structure which is typically tens of microns in length. It is conductive primarily along its planes, with an absolute resistivity of $0.006 \Omega . \mathrm{cm}$. [9, 10] GNPs consist of tens to hundreds of carbon layers and are a little more expensive than graphite, but due to their smaller size and higher aspect ratio, can produce smoother prints [9, 11, 12]. Carbon black is an amorphous form of carbon, consisting of nearly spherical primary particles of a much smaller characteristic size than graphitic carbons, fused together in aggregates with a high surface area $[10,13]$. When compared with the other morphologies of carbon, carbon black has a high percolation threshold for electron conduction. This is due to the large contact resistance between carbon black particles [2]. Therefore, it is typically combined with larger carbon morphologies such as graphite or GNPs in inks, where they can be readily dispersed to form conductive bridges between neighbouring graphite flakes or GNPs to enhance the electrical conductivity of the ink $[10,14]$.

Studies investigating the effect of different ratios of carbon black in graphite or GNP-based inks found that correct ratios were able to improve the inks electrical performance and lead to reductions in the percolation threshold [10, 14-17]. However, they also found that higher concentrations of carbon black led to increased print roughness due to print defects such as agglomerations or mesh marking. Mesh marking is where there are significantly raised areas in the print profile which correspond with the frequency of the mesh used that in severe cases are surrounded by areas of little or no ink deposit [18]. All screen-printed features are produced by some merging of the ink which flows through between the threads. Mesh marking results when this merging does not occur and can be attributed to a high near rest viscosity due to the large number of particle-particle interactions. These defects can have detrimental effects on the electrical performance of the print. Therefore, further investigations into how individual particles behave would be beneficial to the understanding of their influence on ink rheology and subsequent print continuity and electrical performance.

The concentration of carbon particles and flakes in an ink can have a significant effect on the conductivity and resistivity of the composite printed film produced. Percolation models have been used to describe the relationship between resistivity and the concentration of conductive particles in an insulating matrix, such as a polymer base used in screen-printing inks [19-21]. However, the percolation equations are typically only valid near the threshold, such as when the composite moves from a perfect insulator to conductor, as well as when the matrix phase is a perfect insulator.

There is a lack of published literature on the optimal concentration of individual carbon morphologies and how significantly they can affect the electrical performance of inks for concentrations above the percolation threshold. There is a trade-off between the particle loading and printability. More carbon should lead to a more conductive ink, but excessive carbon concentrations could lead to agglomerations of particles and increased surface roughness, exceeding a certain carbon conductor mass fraction could lead to print defects (such as mesh marking) which impinge upon the electrical performance of the 
ink [10, 22]. Different filler (carbon) concentrations also alter the rheological profile of the ink, which can be quantifiably related to the quality of the print produced [23, 24]. High speed imaging techniques have been used by $\mathrm{Xu}$ and Willenbacher [25] and the authors [26] to identify how the rheological profiles of screen printing inks influence the inks deposition and separation mechanism during screen printing. $\mathrm{Xu}$ and Willenbacher's [25] study on fine line screenprinted $\mathrm{ZnO}$ pastes imaged the print process from directly below a glass substrate, looking up at the print. This identified the influence of ink rheology on the amount of paste spread at the edge of the features, due to the ink slumping after it has been deposited which can affect line resolution. Previous studies by the authors conducted high speed imaging from the side of a custom-made screen-printing apparatus, enabling the ink deposition and separation mechanisms to be visualised for a range of parameter settings and dilutions of a commercial carbon ink containing graphite and carbon black $[26,27]$. The study assessing the effect of diluting a commercial carbon ink on the separation mechanisms occurring during screen-printing found that changes in the rheological profile of the carbon-based ink had quantifiable effects on the ink separation mechanisms during screen printing. These separation mechanisms were found to be related to the print quality produced (surface roughness and presence of print defects such as mesh marking) and resultant print conductivity [26].

However, these studies were limited to a single ink with mixed carbon morphologies, so it could not be determined whether the particle shape influenced the ink separation mechanisms and resultant print profile.

Therefore, a study was undertaken to improve the understanding of how graphite, carbon black and GNPs influence the inks rheological profile, separation mechanisms and resultant print profile and conductivity. A series of inks were manufactured under consistent and controlled conditions using different concentrations of individual carbon morphologies and polymer. Shear rheometric analyses were conducted to quantify the differences in viscosity and viscoelasticity of the inks. High speed imaging of the printing process was conducted using custom-made screen-printing apparatus to visualise and quantify the ink separation stages occurring during printing [27]. Comparison prints were made on a commercial screen-printing press. Film thickness, surface roughness, resistance and resistivity measurements of the resulting prints were conducted to establish the impact of formulation and deposition characteristics on the electrical performance.

\section{Materials and Methods}

\section{Inks}

Inks containing graphite, graphite nanoplatelets (GNP) and carbon black were made with an ethyl cellulose resin base (with $12.5 \%$ by weight dry polymer, ethyl cellulose (200,697 Aldrich, Sigma-Aldrich) in 4-hydroxy-4-methylpentan-2-one (H41544 Aldrich, Sigma-Aldrich)). Carbon materials used were as follows: graphite (Timrex ${ }^{\circledR}$ SFG15, Imerys Graphite and Carbon; typical D90 $17.9 \mu \mathrm{m}$ according to manufacturer, absolute resistivity: $0.75-1.75 \Omega . c m$ [28]); carbon black (TIMCAL ENSACO ${ }^{\mathrm{TM}}$ 250G Conductive Carbon Black Compounds; with diameter distribution from 20 to $50 \mathrm{~nm}$ and specific surface area of 65 $\mathrm{m}^{2} / \mathrm{g}$ according to the manufacturer) and graphite nanoplatelets (GNPs) functionalised with oxygen (GNP-O2 produced by Haydale Ltd. with average flake diameter around $5 \mu \mathrm{m}$ ).

The concentrations used for each carbon morphology (expressed in weight percentage $(w t \%))$ are shown in Table 1, where an $x$ denotes that a given loading percentage was used. When making the inks, the carbon materials were gradually added and stirred in to the pre-made resin by hand. The carbon concentration range was limited at the low end by conductivity requirements (especially for graphitic carbon) and at the high end by excessive viscosity and poor film forming (especially for carbon black). For each carbon morphology, three different carbon concentrations were used, spanning the usable range, with graphitic carbons loaded between 15 and $25 \mathrm{wt}$ $\%$ and carbon black between 10 and 20\%. The ink slurries were then left to wet overnight before triple roll milling. This is conducted to improve the dispersion of the carbon in the ink and to avoid agglomerations of particles and flakes. Milling was conducted with an EXAKT80E three roll mill (EXAKT Advanced Technologies $\mathrm{GmbH}$ ) with the same processing conditions used for all inks, as presented in . 
Table 1 Ink batch composition for carbon-based inks

\begin{tabular}{lllll}
\hline Carbon Morphology used in ink & \multicolumn{4}{c}{ Different loadings used for each carbon morphology in terms of mass \% } \\
\cline { 2 - 5 } & 10 & 15 & 20 & 25 \\
\hline Graphite wt\% & - & $\mathbf{x}$ & $\mathbf{x}$ & $\mathbf{x}$ \\
Carbon black wt\% & $\mathbf{x}$ & $\mathbf{x}$ & $\mathbf{x}$ & - \\
GNP wt\% & - & $\mathbf{x}$ & $\mathbf{x}$ & $\mathbf{x}$ \\
\hline
\end{tabular}

Table 2 Triple roll mill settings

\begin{tabular}{llll}
\hline Pass number & Back Gap $(\mu \mathrm{m})$ & Front Gap $(\mu \mathrm{m})$ & Front roller (rpm) \\
\hline 1 & 60 & 15 & 200 \\
2 & 40 & 10 & 200 \\
3 & 20 & 5 & 200 \\
\hline
\end{tabular}

Table 2. Further mixing was conducted prior to printing, using a Speedmixer (Speedmixer ${ }^{\mathrm{TM}}$ DAC 150.1 (FVZ-K)), for $5 \mathrm{~min}$ at $2500 \mathrm{rpm}$.

\section{Rheological testing}

Rheological evaluation was carried out using a combination of shear, viscoelastic and extensional measurements on the inks. Analyses were conducted with a TA Instruments AR-G2 rheometer. A roughened $60 \mathrm{~mm}$ stainless steel parallel plate geometry held at $20{ }^{\circ} \mathrm{C}$ was used for conducting the tests. Prior to conducting the tests, viscosity measurements were conducted over a range of gap distances to choose a suitable gap height between the plates to prevent slip from occurring. Ink viscosity was measured as the shear rate was increased from $0.1 \mathrm{~s}^{-1}$ to $100 \mathrm{~s}^{-1}$ with 5 logarithmically spaced measurements per decade. Small amplitude oscillatory shear (SAOS) [24] was used to measure the viscoelastic profile of each ink between $0.1 \mathrm{~Hz}$ and $10 \mathrm{~Hz}$. Measurements were performed within the linear viscoelastic region (LVR) of the inks.

The yield stress was determined using a series of creep experiments with stresses logarithmically spaced from $0.1 \mathrm{~Pa}$ to $750 \mathrm{~Pa}$ applied for $60 \mathrm{~s}$. The sample was allowed to reach steady state for the samples measured recovery time prior to measurement of the shear stress. In determining the yield stress, the point at which compliance increases linearly with time the material is determined to have fully yielded [29]. For this study, the stress is calculated as the value at which the compliance increases linearly after $1 \mathrm{~s}$. By identifying the time at which the material yields at a number or stresses, the yield stress at $1 \mathrm{~s}$ can be extrapolated.

\section{Ink separation mechanisms during printing}

Screen printing for the high speed imaging of the ink separation mechanisms was conducted on a custommade screen-printing apparatus (described in detail previously [27]). This enabled the mesh-substrate separation to be visualised during the print process using a high-speed camera (Photron FastCam Mini High-Speed Camera) at a frame rate of 125 frames per second. Squeegee motion in the print direction ( $x$ axis) and vertical movement perpendicular to the print direction ( $\mathrm{z}$ axis) was controlled by stepper motors powering lead screws on linear actuators. It was programmed using Arduino with Grbl Controller 3.0 (open source) software to set the speed and distance of the movement. This allowed the squeegee to be brought in to contact with the screen, then brought across the screen to transfer the ink.

A polyester mesh at $22.5^{\circ}$ with 61 threads per $\mathrm{cm}$, $64 \mu \mathrm{m}$ thread diameter and 12-micron emulsion over mesh (EOM) was used to print the image. A 65-70 Shore A hardness diamond squeegee was used, along with a snap distance (distance between screen and substrate) of $1.825 \mathrm{~mm}$ and squeegee travel speed of $300 \mathrm{~cm} / \mathrm{min}(50 \mathrm{~mm} / \mathrm{s})$. The substrate was PET (polyethylene terephthalate-Melinex ${ }^{\circledR}$ 339, DuPont Teijin Films (175 $\mu \mathrm{m}$ thickness) opaque white). The print image consisted of a continuous $200 \mu \mathrm{m}$ wide line in the direction of squeegee travel. The ink separation was quantified with two key regions, consisting of the adhesion to extension region (where the 
ink remains in continuous contact with the mesh and substrate), and the flow to separation region (where the main body of ink splits off into filaments which eventually separate) (Fig. 1). A total of 45 sets of measurements were taken for each ink ( 3 prints high speed imaging data assessed from a batch of 10 (prints 2,6,10), with 15 sets of measurements conducted for each print across evenly spaced intervals in the region assessed with high-speed imaging) from which the standard deviation in each of the print stages for each ink was calculated.

\section{Screen-printing with commercial press}

Printing was carried out on a DEK 248 flatbed screen printing machine using a polyester mesh containing 61 threads per $\mathrm{cm}, 64 \mu \mathrm{m}$ thread diameter and 13-micron emulsion over mesh (EOM). A 65-70 Shore A hardness diamond squeegee of $130 \mathrm{~mm}$ length with snap off distance of $1 \mathrm{~mm}$, with a downward squeegee force of $9 \mathrm{~kg}$ and print/flood speed of $70 \mathrm{~mm} \mathrm{~s}^{-1}$, was observed. The substrate used was PET (polyethylene terephthalate-Melinex® 339, DuPont Teijin Films (175 $\mu \mathrm{m}$ thickness) opaque white), as was used for the ink separation visualisation. The print image included a series of 25-mm-long lines of nominal widths from $100 \mu \mathrm{m}$ to $700 \mu \mathrm{m}$ and a $45-\mathrm{mm}$ square solid patch for sheet resistance and resistivity assessment. Printed samples were dried in a conveyor dryer at $100{ }^{\circ} \mathrm{C}$ for $5 \mathrm{~min}$.

\section{Printed line topography and microstructure}

White light interferometry (NT9300, Veeco Instruments, Inc., Plainview, NY, USA) was used to measure a full three-dimensional surface profile of the printed lines (produced on the DEK 248 screen printed). The ink film thickness was calculated as the average height of the substrate subtracted from the average height of the ink. Five times magnification was used, giving a measurement area of $1.2 \mathrm{~mm}$ by $0.93 \mathrm{~mm}$ (at a resolution of $736 \times 480$ pixels with sampling at $1.67 \mu \mathrm{m}$ intervals). A total of 12 measurements were conducted for each line width to calculate the average and standard deviations in line width and thickness. For the printed squares (produced on the DEK 248 screen printed), analyses were conducted in the centre of the print for average surface roughness $(\mathrm{Sa})$ and average maximum surface roughness $(\mathrm{Sz})$ values. The printed film thickness was
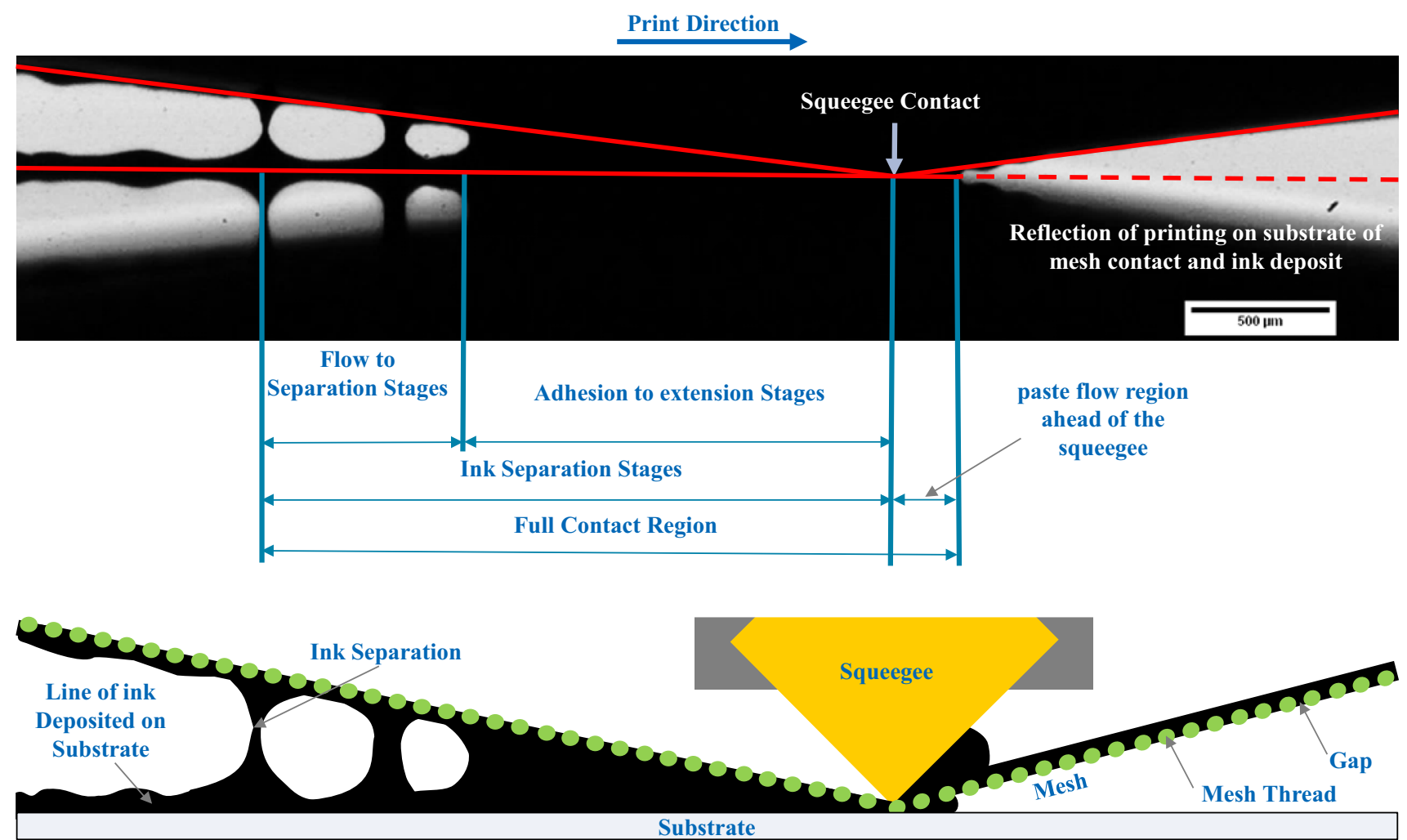

Figure 1 Labelled high-speed camera image identifying the different stages occurring during ink deposition and separation [27].

\section{Springer}


evaluated by measuring over the edge of the solid print. A total of 12 measurements were conducted for each ink for both surface roughness and film thickness, from which the standard deviation in film thickness and surface roughness was calculated.

The microstructure of the prints was assessed using a JEOL JSL 7800F FEG scanning electron microscope (SEM) $(4 \mathrm{kV}$ acceleration voltage, a working distance of $9 \mathrm{~mm}$ and magnifications of $x$ 3000 and $\times 10,000$ ).

\section{Electrical characterisation}

Dry film conductivity was the primary means used to determine the performance suitability of different carbon concentrations. Two- and four-point probe measurements were conducted to find the line resistance, sheet resistance values of the printed lines and squares produced on the DEK 248 screen printer. The sheet resistance measurements were conducted on the printed $45 \times 45 \mathrm{~mm}$ squares using a 4-point probe method. A SDKR-13 probe (NAGY Messsysteme $\mathrm{GmbH}$ ) with a tip distance of $1.3 \mathrm{~mm}$ was used with a Keithley 2400 digital sourcemeter, with subsequent conversion to sheet resistance using the appropriate correction factor from the data table proposed by Smits [30]. Sheet resistances are displayed as measured and resistivities were calculated as the product of sheet resistance and ink film thickness to account for the thickness variation in the dry film. A total of 12 sheet resistance values were taken across the centre of each printed square to account for any deviation in print quality across the area, with three printed samples analysed, giving a total of 36 measurements for each ink, from which the average values and standard deviations were calculated. Line resistance was measured also using a Keithley 2400 digital Sourcemeter in two-point mode for the $700 \mu \mathrm{m}, 500 \mu \mathrm{m}$ and $300 \mu \mathrm{m}$ nominal width lines over three prints for each of the inks to calculate the average value and standard deviation.

\section{Results}

\section{Rheological Analyses}

The viscosity and viscoelasticity profiles of the inks are shown in Figure. All the inks and the plain resin demonstrated shear thinning behaviour, with the greatest reductions in viscosity occurring before $20 \mathrm{~s}^{-1}$ (Figure a). Increasing the loading percentage of carbon led to increases in viscosity over all shear rates for all morphologies. This is likely to be due to the increase in particle to particle interactions associated with the relative volume of carbon particles in the solvent-resin matrix, preventing the particles from aligning with the flow, as seen by Claypole et al. [24]. There would also be more hydrodynamic disturbance in the flow field, as the number of particles for it to be diverted around increase [24]. Although the inks containing $25 \mathrm{wt} \%$ of graphite and $20 \mathrm{wt} \%$ carbon black could not be assessed at shear rates beyond $10 \mathrm{~s}^{-1}$ and $15 \mathrm{~s}^{-1}$ as the high viscosities of the inks prevented the rheometer from rotating at these speeds, with viscosities of $95.5 \mathrm{Pas}$ and $48.5 \mathrm{~Pa} \mathrm{~s}$, respectively, at these final shear rates. These two inks also had the highest initial viscosities.

The carbon black (CB) inks were found to have significantly higher viscosities at low shear rates than the graphite or GNP inks for comparable weight concentrations. Carbon black has a smaller particle size and higher specific surface area than GNPs and graphite. Their smaller size also resulted in a far greater number of particles for a comparable weight concentration, resulting in many more interactions. This would result in smaller interparticle spacing and more resistance to interparticle slippage resulting in these higher viscosities at low shear rates [10, 31]. At higher shear rates, these relatively weak particleparticle interactions can be overcome, leading more significant reductions in viscosity at high shear rates than with the graphite and GNP inks. The high aspect ratios and relatively larger size of graphite and GNPs resulted in far fewer particle-particle interactions and therefore lower viscosities. The inks containing 15 wt $\%$ and $10 \mathrm{wt} \%$ carbon black reduced to viscosities of 8.0 Pas and 7.1 Pas, respectively, at shear rates of $100 \mathrm{~s}^{-1}$. The graphite-based inks with $20 \mathrm{wt} \%$ and 15 wt \% loading have viscosities of 11.3 Pas and 6.6 Pas, respectively, at $100 \mathrm{~s}^{-1}$. The inks loaded with $25 \mathrm{wt} \%$, $20 \mathrm{wt} \%$ and $15 \mathrm{wt} \%$ GNP's have viscosities at $100 \mathrm{~s}^{-1}$ of 11.0 Pas, 7.5 Pas and 5.5 Pas, respectively.

Increases in carbon concentration led to reductions in phase angle for all morphologies, at all measured frequencies (Fig. 2b). The small, spherical carbon black particles had more surface area in contact with one another than the high aspect ratio, randomly oriented GNPs and graphite flakes, leading to a greater elastic response. The GNP and graphite-based 


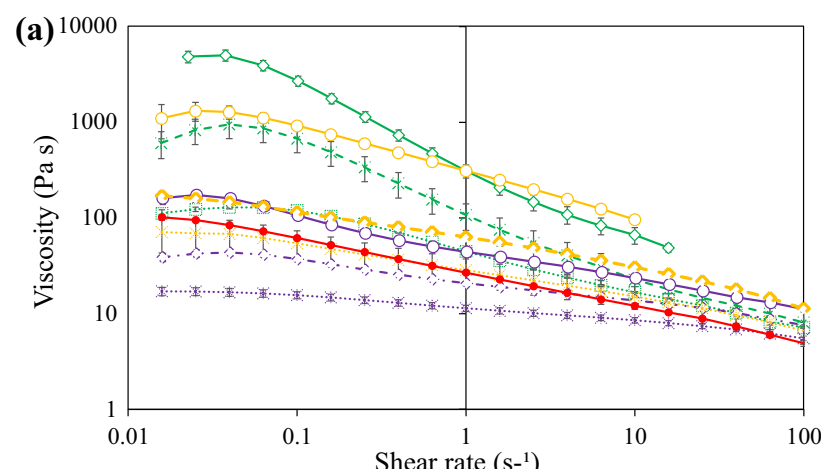

(b)

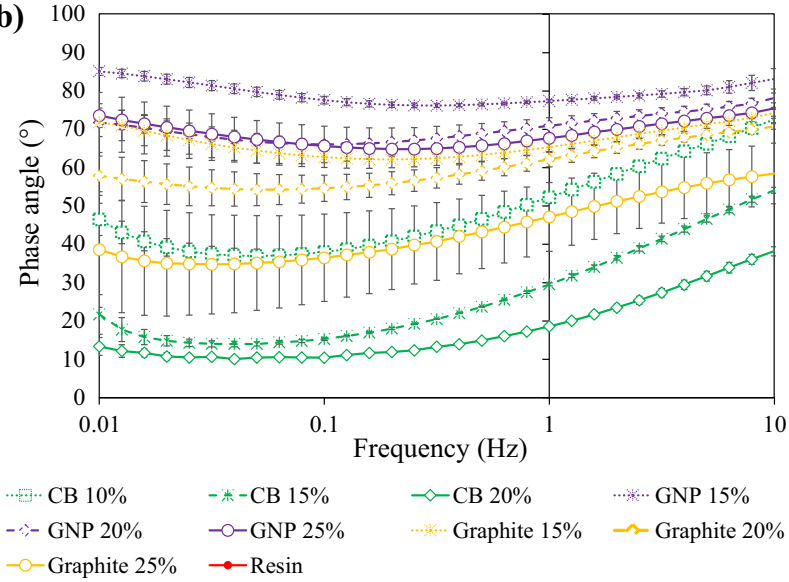

Figure 2 Viscosity profiles (a) and viscoelasticity profiles assessing changes in phase angle $(\delta)(\mathbf{b})$ of the varying carbon morphologies and loading percentages for carbon black (CB), GNPs and graphite (G). (Error bars represent standard deviation).

inks had lower phase angles with a more liquid-like behaviour. The GNP-based inks had the highest phase angles. This could be a result of having less variation in platelet sizes than the graphite flakes that ranged from 5 to $30 \mu \mathrm{m}$ wide. This range of flake size would increase packing factor and the area of flakes in contact, leading to a more elastic response than the GNP-based inks.

As with viscosity, the yield stress increases in a near exponential relationship, as shown in Table 3. The $20 \mathrm{wt} \%$ carbon black ink had a yield stress that was too high to determine, illustrating the dramatic increase in initial resistance to flow as solids content increases. This increase to a significantly higher yield stress also correlates to a decrease in print performance. Although such a correlation provides a strong indication of processability problems the technique is not sensitive enough to use as a predictive tool.

\section{Ink separation mechanisms during printing}

An illustration of the ink deposition mechanisms at the various dilutions is shown in Fig. 3. Images of the print interface are shown along with a chart of the relative lengths of each of the printing stages (as outlined in Fig. 1 [27]). There were more filaments formed during separation, as well as a greater contact distance between both the mesh and substrate after the squeegee contact point, in the more viscous inks (Fig. 3). There were negligible changes in the length of paste flow ahead of the squeegee, but large changes in the length of the adhesion to extension stages, where the ink remained in continuous contact with the mesh and substrate simultaneously. More significantly, the flow to separation stages, where the main body of ink splits off into filaments which eventually separate, were found to cease in some of the less viscous inks.

The plain resin exhibited all four stages of ink separation. However, the filaments forming during the flow to separation stages exhibited a cascade effect, where the outermost filaments would flow back towards the print direction and merge with the next filament forming on most occasions, rather than continuing to elongate and then separate. This is shown in more detail in Fig. 4, where the filaments appear to move back towards the main body of the extended ink over the duration of the squeegee moving across the mesh during printing.

There was an overall increase in the average full contact region length with increases in graphite concentration and increases in ink viscosity and elasticity. The graphite-based inks containing $15 \mathrm{wt} \%$ and $20 \mathrm{wt} \%$ carbon loading also behaved in a manner similar to that of the plain resin, (Fig. 3). The

Table 3 Yield Stress of inks

\begin{tabular}{lcccc}
\hline Carbon morphology used in ink & \multicolumn{4}{c}{ Yield stress (Pa) of concentrations of each carbon type } \\
\cline { 2 - 5 } & $10 \mathrm{wt} \%$ & $15 \mathrm{wt} \%$ & $20 \mathrm{wt} \%$ & $25 \mathrm{wt} \%$ \\
\hline Graphite & - & 143.6 & 402.3 & 843.3 \\
Carbon black & 130.5 & 226.0 & Too high to measure & - \\
GNP & - & 1.8 & 61.6 & 157.1 \\
\hline
\end{tabular}


Figure 3 High-speed camera images at $5 \times$ magnification and quantification of the average print stage lengths for deposition of the plain resin (a) along with the ethyl cellulose-based carbon inks loaded with varying amounts of graphite (b to $\mathbf{d}$ ), GNPs (e to $\mathbf{g}$ ) and carbon black (h to j). (Error bars for standard deviation).
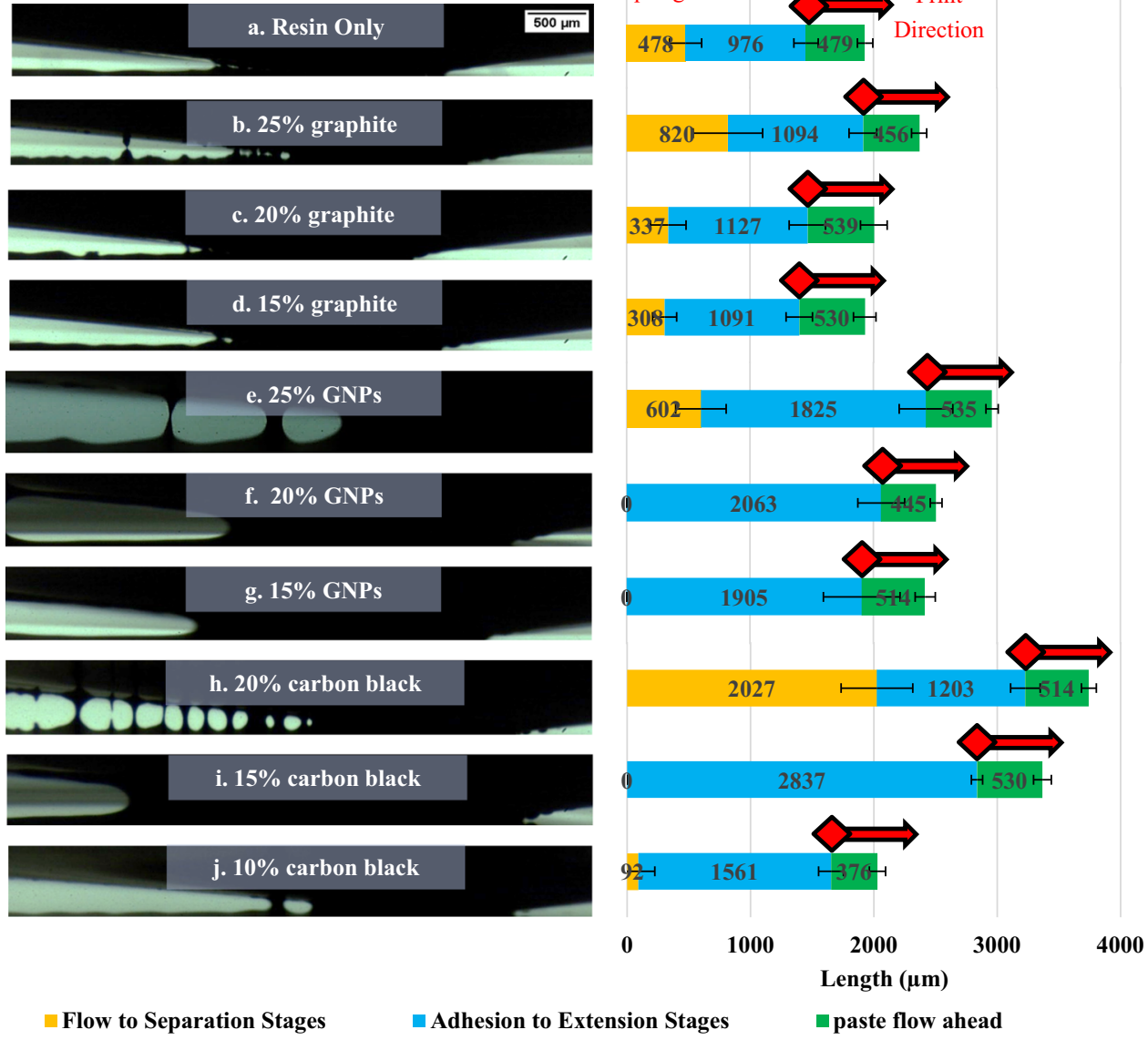
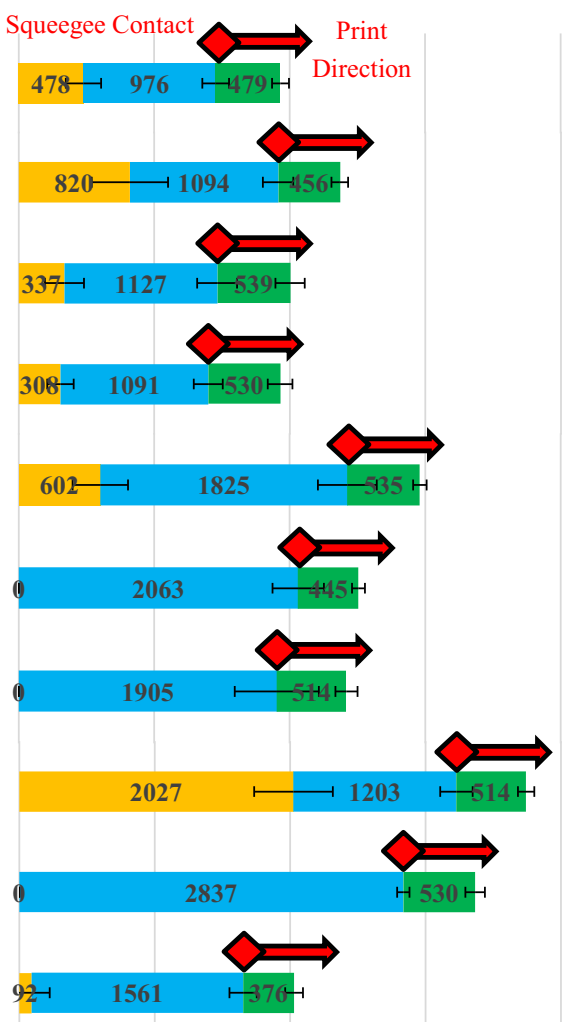

Length $(\mu \mathrm{m})$

paste flow ahead

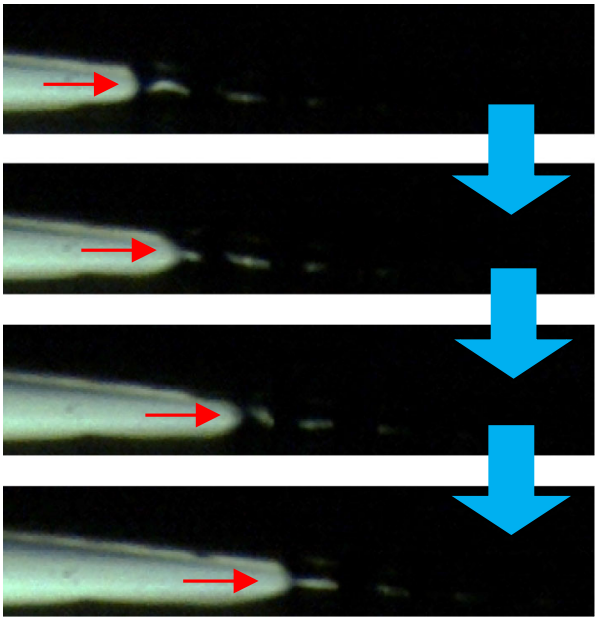

Figure 4 High-speed camera images at $5 \times$ magnification of different stages of the deposition of the plain resin showing the merging of the filaments forming during separation.

dominos-like effect was also seen with these inks during separation, where the filaments forming at the end of the separation stages would flow into the next forming filaments. However, the lengths of the flow to separation stage lengths of the $15 \mathrm{wt} \%$ and $20 \mathrm{wt} \%$ graphite-based inks were slightly shorter than those observed with the plain resin and their adhesion to extension stages were slightly longer. The $25 \mathrm{wt} \%$ graphite-based ink had a similar average adhesion to extension stage length, but with a far larger average flow to separation stage length. The $25 \mathrm{wt} \%$ loaded ink exhibited a greater number of filaments formed behind the adhesion to extension stages and took longer to separate than with the lower concentrations of graphite. In this case, the dominos-like effect did not occur. Instead, the filaments gradually necked and separated, as with the filaments formed in the extensional rheology tests.

The full contact region was typically longer for the inks containing GNPs. However, the $15 \mathrm{wt} \%$ and 20 wt $\%$ loaded inks exhibited a clean separation behind the adhesion to extension zone without any individual filaments forming. As a result, these inks did not exhibit any flow to separation stages but did have relatively long adhesion to extension lengths. The 25 wt \% GNP ink did exhibit filaments forming, necking 
and separating after the adhesion to extension stages. Although these filaments were far larger and more spread out than in the graphite-based inks. The 25 wt\% GNP ink also had a relatively long average adhesion to extension stage length compared with the profiles of the graphite-based inks. As with the graphite based inks, increases in the GNP concentration led to increases in the full contact region as the ink increases in viscosity and elasticity.

As with the other morphologies, there was an increase in the average full contact region length with increases in the concentration of carbon black and resultant increases in viscosity and elasticity. The carbon black-based inks exhibited the broadest range of deposition profiles out of the carbon morphologies assessed. The $10 \mathrm{wt} \%$ loaded ink had the shortest full contact region length out of the carbon black-based inks, consisting of a relatively short average flow to separation stage length and an average adhesion to extension stage length when compared with the other inks. The 15 wt $\%$ carbon black-based ink did not exhibit a flow to separation stage. As with the $15 \mathrm{wt} \%$ and $20 \mathrm{wt} \%$ GNP inks, there was a clean separation behind the adhesion to extension zone without any individual filaments forming. However, the ink still had a large full contact region, due to having the largest average adhesion to extension stage of all the inks assessed, whereas the $20 \mathrm{wt} \%$ carbon black ink did exhibit filamentation after the adhesion to extension stage, with the largest average flow to separation stage length of all the inks assessed. In this case, there were several filaments formed behind the adhesion to extension stage at one time, with an average adhesion to extension length. This resulted in the largest full contact region length of the inks assessed.

\section{Print Topography}

As there are nuances in the performance of the printed structures between those printed as distinct lines and those printed as large areas, the results are presented distinctly.

\section{Line characteristics}

The average ink film thickness, line widths and crosssectional areas of the lines printed for the different carbon morphologies and their range of concentrations on the DEK 248 screen printer are compared in
Fig. 5. For all carbon morphologies, there were significant increases in the film thicknesses of the $500 \mu \mathrm{m}$ and $700 \mu \mathrm{m}$ nominal width lines with increases in the percentage of the carbon mass in the inks (Fig. 5). There were gradual increases in film thickness with carbon loading for the GNP and carbon black-based inks, while the graphite-based inks had a significant increase in height when going from $15 \mathrm{wt} \%$ to $20 \mathrm{wt} \%$, but had a smaller change when increasing to $25 \mathrm{wt} \%$.

For all carbon morphologies, there were reductions in line width with increases in carbon loading. The carbon black-based inks had the most significant reductions, with the $700 \mu \mathrm{m}$ nominal width lines reducing by almost $300 \mu \mathrm{m}$. The average line widths of the GNP and graphite-based inks were within $20 \mu \mathrm{m}$ of each other for the lower carbon concentrations, although the width of the graphite lines significantly reduces at $25 \mathrm{wt} \%$. This resulted in an overall increase in the cross-sectional area (CSA) of ink deposited with increases in carbon concentration, as shown in Fig. $5 \mathrm{c}$ for the $500 \mu \mathrm{m}$ nominal width lines. The GNP-based inks saw a gradual increase in CSA with carbon loading, while the graphite- and carbon black-based inks medium loading produced the highest CSA. This was most significant with the graphite-based inks where the CSA for the $20 \mathrm{wt} \%$ ink was over $1000 \mu \mathrm{m}^{2}$ higher than the CSA for the $25 \mathrm{wt} \%$ ink.

\section{Solid print area}

The average ink film thickness and surface roughness of the printed squares produced on the DEK 248 screen printer are shown in Fig. 6, along with corresponding topography images (Fig. 6c). The carbon morphology and loading had a significant impact on the thickness and topological nature of the printed film within the solid area (Figs. 6). There is a stepwise increase in the film thickness with the increase in carbon content which is in line with that observed with the printed lines (Fig. 6a).

The topography images (Fig. 6c) show a significant increase in print roughness with loading for all morphologies, with the formation of agglomerates and print defects such as mesh marking. Mesh marking is identified as regular features corresponding with the frequency of the mesh that are usually caused by higher ink viscosities. By splitting the surface topology surface roughness (Sa) into two 
Figure 5 Average film thickness (a) and line width (b) of the $500 \mu \mathrm{m}$ and $700 \mu \mathrm{m}$ lines, with the cross-sectional area of the $500 \mu \mathrm{m}$ lines (c) produced by the carbon inks containing different carbon morphologies and different loading ratios. (Error bars for standard deviation).
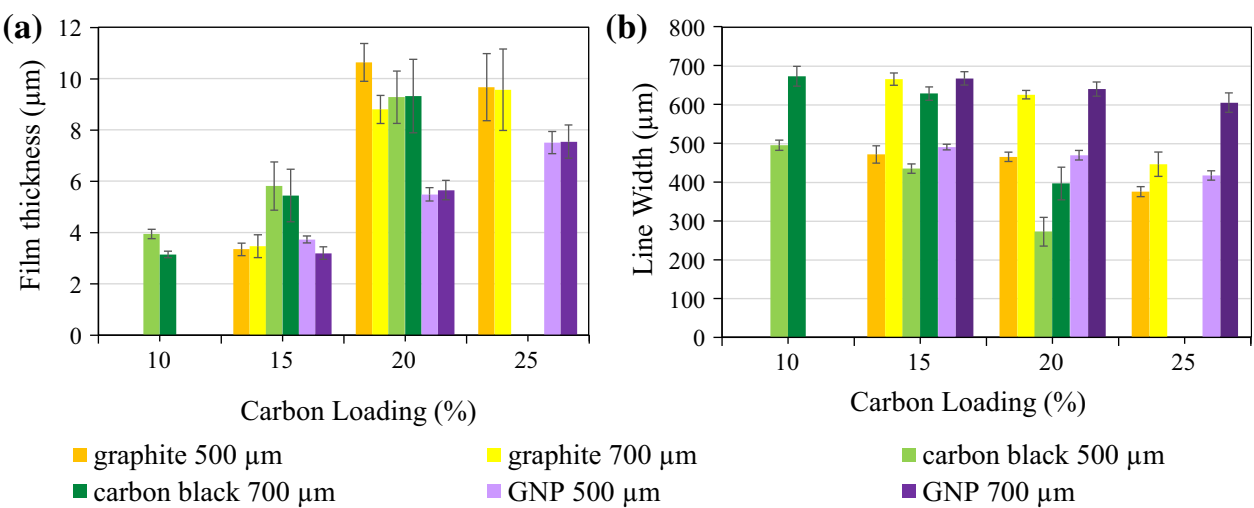

$$
\begin{array}{ll}
\square \text { graphite } 500 \mu \mathrm{m} & \text { graphite } 700 \mu \mathrm{m} \\
\square \text { carbon black } 700 \mu \mathrm{m} & \square N P 500 \mu \mathrm{m}
\end{array}
$$$$
\text { - GNP } 700 \mu \mathrm{m}
$$

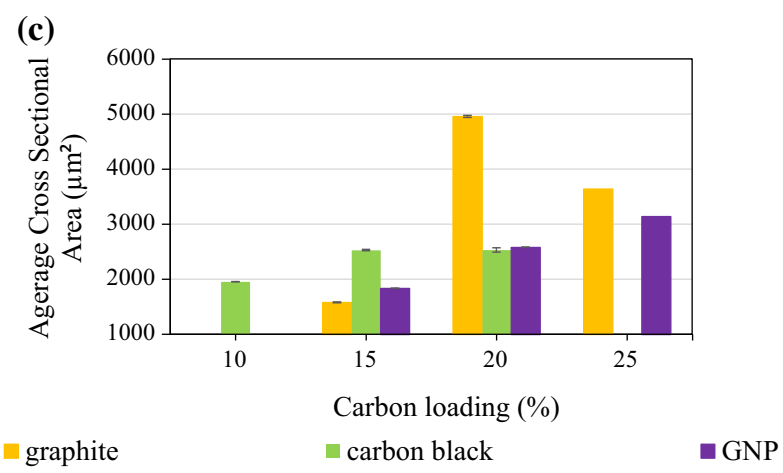

scales, the effect of particle geometries could be identified on the shorter wavelength scale, of the $2-50 \mu \mathrm{m}$ range. Whereas above $50 \mu \mathrm{m}$, the longer scale undulations at a wavelength were indicative of the presence of mesh marking. The presence of mesh marking was particularly visible for the print film surface of the $20 \mathrm{wt} \%$ carbon black ink, as shown in in Fig. 6c (vi). This displayed a large wavelength of around $150 \mu \mathrm{m}$, which corresponds with the frequency of the mesh (61 threads per $\mathrm{cm}$ resulting in a gap of $156 \mu \mathrm{m}$ between the peaks of threads). The formation of mesh marking leads to a notable increase in the surface roughness (Sa) of the $20 \mathrm{wt} \%$ carbon black ink, when compared to the $10 \mathrm{wt} \%$ and $15 \mathrm{wt} \%$ inks (Fig. 6b). Despite the $20 \mathrm{wt} \%$ carbon black ink demonstrating the most significant mesh marking patterns out of all the inks, the carbon black inks had significantly lower surface roughness (Sa) than those of the graphite and GNP inks, due to the effect of particle size.

The larger graphite particles formed a random particulate platelet structure, with some protruding from the ink surface (Fig. 6c). This resulted in increases in the shorter wavelength surface roughness. Increases in the graphite loading lead to agglomerates of randomly oriented large flakes. This significantly increased the average surface roughness with increase in concentrations. The relatively large size of the graphite flakes when compared to the GNPs and carbon black particles resulted in far higher surface roughness (Sa) than the other morphologies for all concentrations (Fig. 6b). The carbon black inks produced relatively smooth print films with variations in height due to the comparable size of the GNPs (Fig. 6c). As with graphite, increases in carbon concentration lead to agglomerates of randomly oriented platelets. As with graphite, the highly loaded GNP-based ink also exhibited relatively short wavelengths in the surface roughness profiles due to the random orientations of the GNPs (Fig. 6b). However, there was a far smaller height variation between the peaks and troughs due to the comparably smaller size of the GNPs when compared with graphite.

When comparing the topography images with the high-speed imaging separation profiles, the significant increases in surface roughness and print defects correspond with a significant increase in filamentation during ink separation (Fig. 7). For the $20 \mathrm{wt} \%$ carbon black ink, there is a significant amount of filamentation occurring prior to ink separation, leading to a series of peaks and troughs in the print profile 

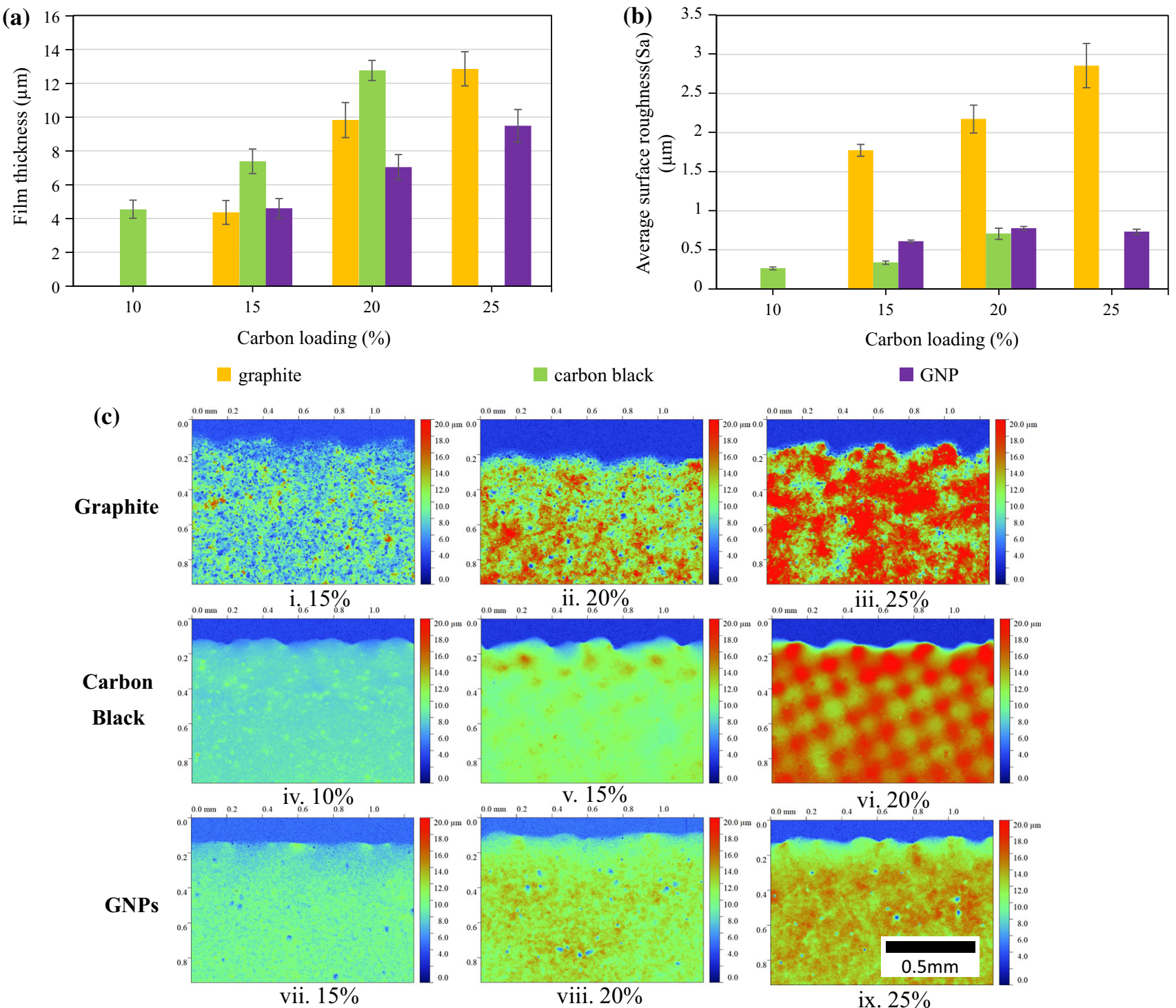

Figure 6 Average film thickness (a) and surface roughness (Sa) (b) of the printed squares (error bars for standard deviation, with corresponding white light interferometry topography images of the printed solid area conducted for the inks (c) at 5 times magnification.

which contribute to mesh marking. Whereas in the case of the $15 \mathrm{wt} \%$ carbon black ink, there is little filamentation formed during ink separation, corresponding with significantly lower surface roughness and little sign of mesh marking. Similarly, increases in the number of filaments formed during ink separation go from $20 \mathrm{wt} \%$ to $25 \mathrm{wt} \%$ loading in the graphite-based inks, resulting in increases in surface roughness and the formation of agglomerations of graphite flakes where the larger filaments separate.

The microstructures of the printed ink films were compared using SEM, as shown in Fig. 8. In the graphite-based inks, the flakes were deposited in a random orientation for both $15 \mathrm{wt} \%$ and $25 \mathrm{wt} \%$ loading, ranging between $0^{\circ}$ and $90^{\circ}$ to the plane of the substrate (Fig. $8 \mathrm{a}$ and b). Similar results were found for the GNP-based inks, where both $15 \mathrm{wt} \%$ and $25 \mathrm{wt} \%$ loadings showed the GNPs to be well dispersed and lying at a range of orientations (Fig. 8c and $\mathrm{d}$ ). However, both the $15 \mathrm{wt} \%$ loaded graphite and GNP-based inks displayed more binder between the flakes and nanoplatelets thank in the $25 \mathrm{wt} \%$ loaded inks. The binder can be identified as the smoother surfaces bridging between the flakes.

The carbon black-based inks displayed the most significant reduction in the distances between the neighbouring conductive particles, as shown in Fig. $8 \mathrm{e}$ and $\mathrm{f}$. In the $10 \mathrm{wt} \%$ carbon black-based ink,

\section{Springer}



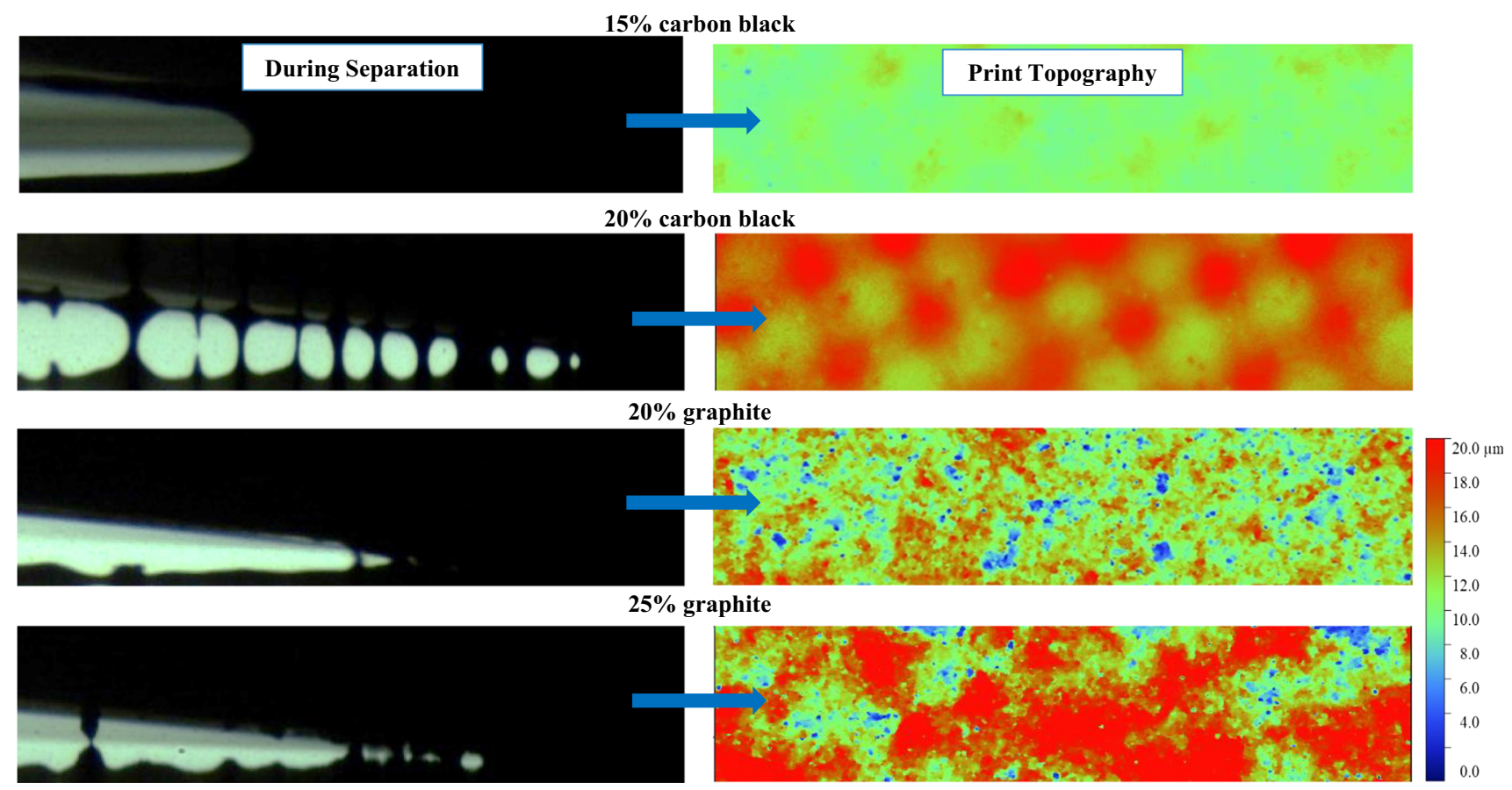

Figure 7 Comparison between the high-speed imaging separation profiles and the resultant print topography produced for 15 wt $\%$ and $20 \mathrm{wt} \%$ carbon black-based inks, as well as $20 \mathrm{wt} \%$ and $25 \mathrm{wt} \%$ graphite-based inks.

the carbon black particles are all surrounded by resin, insulating agglomerates of carbon black particles from each other. The $20 \mathrm{wt} \%$ ink displayed most particles interacting with one another, with small patches of resin across the surface, leading to more direct electrical connection.

\section{Electrical characterisation}

The resistance data of the prints are shown in Fig. 9. Displaying the average line resistance for the $500 \mu \mathrm{m}$ and $700 \mu \mathrm{m}$ lines (a), as well as the average sheet resistance (b) and volume resistivity (c) of the printed squares. Prints made using carbon black-based inks were found to be the most conductive by orders of magnitude, due to their small size leading to a greater number of particles within the inks. Leading to smaller gaps between particles and significantly more particle to particle interactions than the other morphologies. The next most conductive were the graphite-based inks, with the GNP-based inks producing the highest line and sheet resistances for all loading percentages assessed.

The graphite and GNP-based inks both had significant reductions in line and sheet resistance between $15 \mathrm{wt} \%$ and $20 \mathrm{wt} \%$ loading, followed by comparatively negligible changes in resistance between $20 \mathrm{wt} \%$ and $25 \mathrm{wt} \%$ loading. When film thickness was accounted for, the changes in volume resistivity between 20 and $25 \mathrm{wt} \%$ loading were within standard deviation, with graphite inks producing a volume resistivity of around $0.75 \Omega . \mathrm{cm}$ and the GNP inks producing a volume resistivity of around $1.24 \Omega . \mathrm{cm}$. Therefore, for both graphite- and GNP-based inks, concentrations below $20 \mathrm{wt} \%$ loading had insufficient conductive pathways, while further increases lead to reductions in print quality, as shown in Fig. 6, without significantly improving the conductive pathways in the printed film.

For the carbon black-based inks, changes in line resistance were within standard deviation for all carbon concentrations, although the $20 \mathrm{wt} \%$ ink had the highest average line resistance. Sheet resistance gradually decreased with increase in concentrations from $0.3 \mathrm{k} \Omega$ /square at $10 \mathrm{wt} \%$ to $0.16 \mathrm{k} \Omega$ /square at $20 \mathrm{wt} \%$. However, the volume resistivity increased with greater carbon concentrations with a slight increase in the volume resistivity from $0.14 \Omega . \mathrm{cm}$ at $10 \mathrm{wt} \%$ loading, to $0.16 \Omega . \mathrm{cm}$ at $15 \mathrm{wt} \%$ loading, followed by a larger increase to $0.21 \Omega . \mathrm{cm}$ at $20 \mathrm{wt} \%$ loading. This is due to the significant increase in film thickness, print roughness and print defects including mesh marking occurring with the higher carbon 
Figure 8 Scanning electron microscope (SEM) images showing the microstructure of the inks (a to d) at 3,000-times magnification, and (e) and (f) at 3,000-times magnification and 10,000times magnification on inset image.
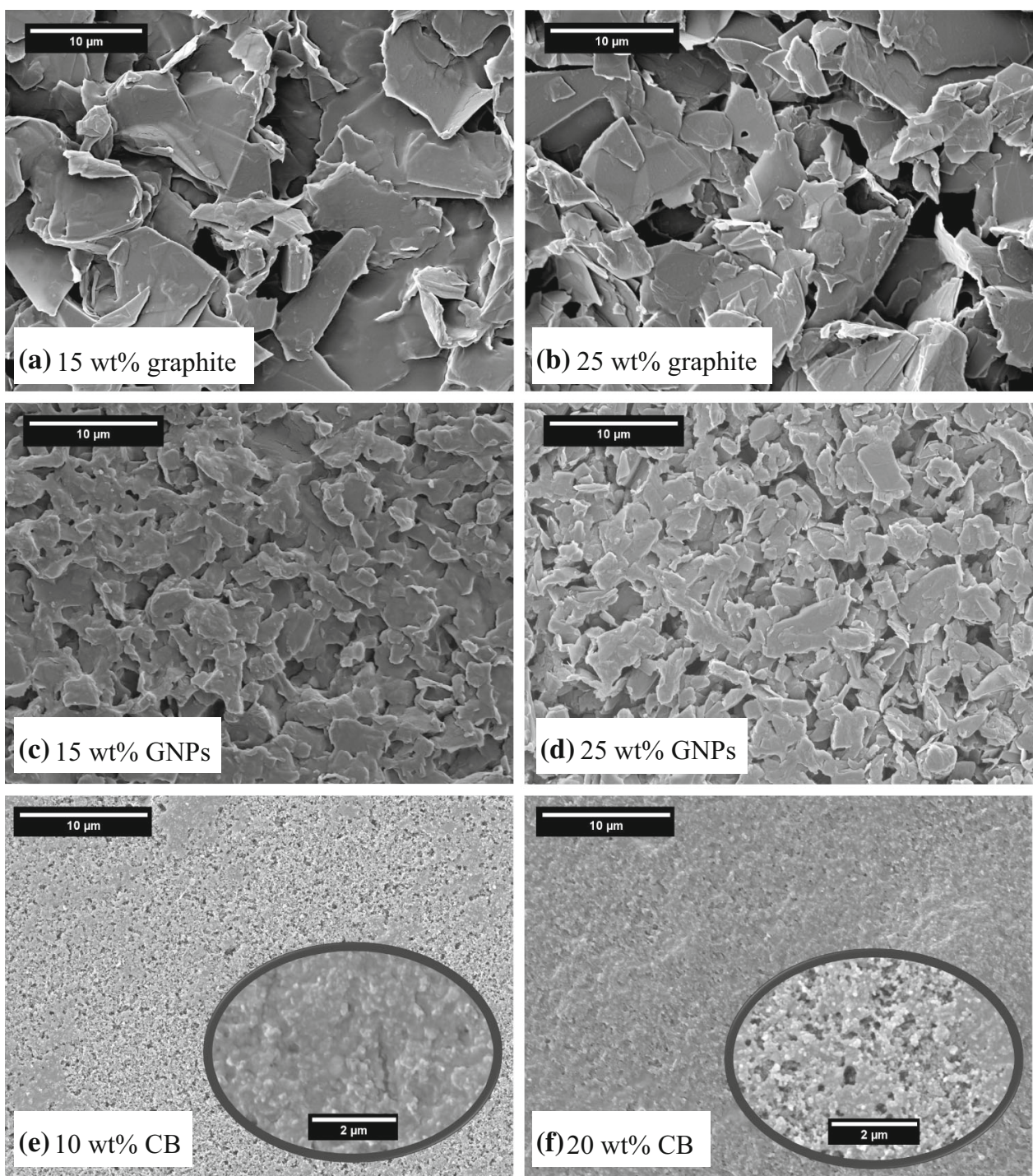

black concentrations, leading to a worse electrical performance when the volume of ink deposited is accounted for.

\section{Discussions}

Carbon black and graphitic carbons have distinctive particle morphologies, which results in a strong divergence in their properties from a printed electronics perspective. Particle size and geometry determines viscosity due to interparticle interactions, which in turn determines the separation of the ink during printing and thus the morphology of the printed ink. In terms of microstructure, smaller more closely packed particles (in a monodisperse system) result in a higher inherent conductivity but defects related to high viscosity/elasticity result in printing defects to the detriment of conductivity. The carbon black-based inks produced the most conductive prints due to their small, spherical shape enabling good particle to particle interactions [32, 33]. However, these particle to particle interactions also led to higher ink viscosities and elasticities than with the other morphologies. This led to severe surface roughness and mesh marking at $20 \mathrm{wt} \%$ concentration. These features also occurred with the other morphologies, although they did not become severe until $25 \mathrm{wt} \%$ with the graphite and GNP-based inks. The graphite-based inks produced the highest print roughness out of the morphologies due to their large flake sizes and random orientation in the print [32]. This led to high viscosities, as with carbon black, but generally less elasticity. The GNP-based inks 
Figure 9 Average line resistance for the $500 \mu \mathrm{m}$ and $700 \mu \mathrm{m}$ lines (a), as well as average sheet resistance (b) and volume resistivity (c) of the printed squares conducted on the DEK 248 Screen printer with all inks compared on the left and the carbon black ink only on the right for the ethyl cellulosebased carbon inks containing different carbon morphologies and different loading ratios. (Error bars for standard deviation). (a)
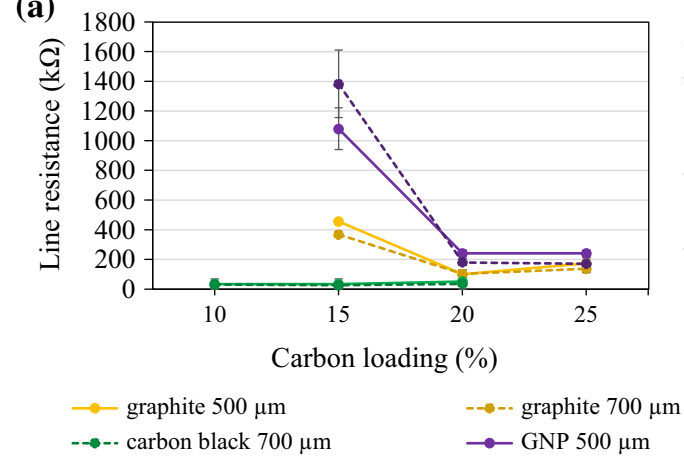

(b)

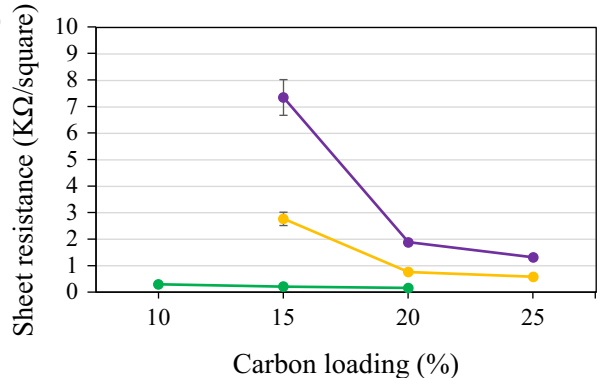

(c)

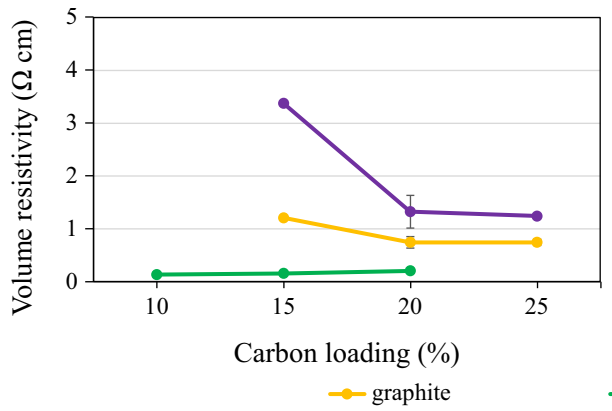

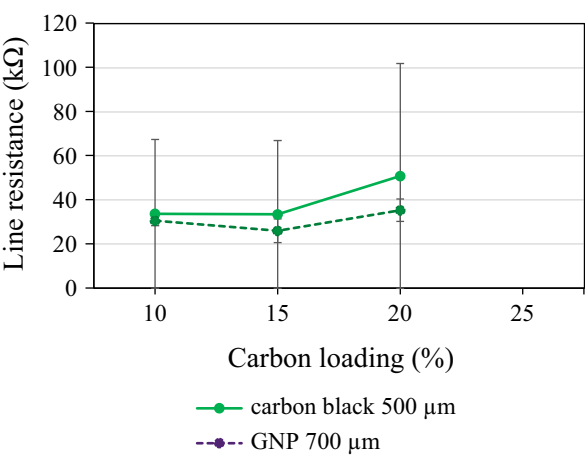
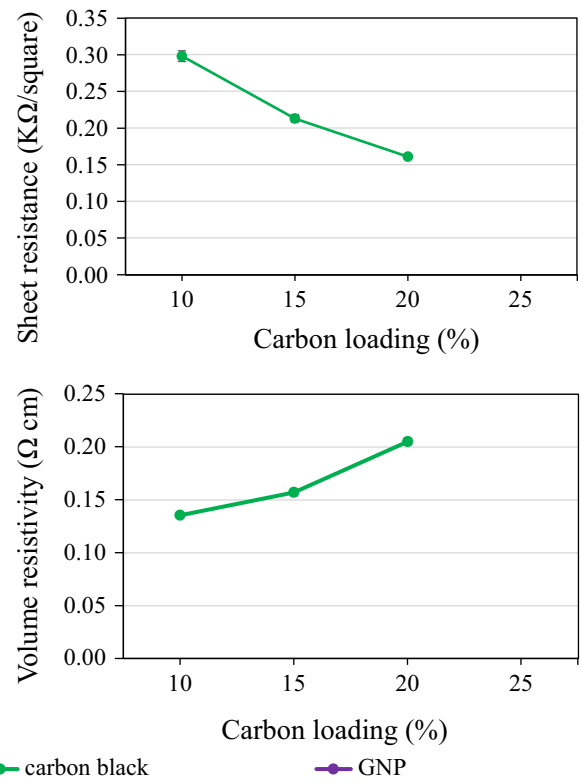

produced the lowest conductivities out of the morphologies due to large gaps between platelets, where the high-aspect-ratio platelets were unable to pack as efficiently as the other morphologies [24]. This also resulted in them having the lowest viscosities and elasticity for comparable concentrations. Although carbon black resulted in the best conductivities for single morphology inks, superior conductivities can be achieved using a combination of different carbon morphologies due to improvements in packing factor and interparticle connections [10, 14, 22]. For combinations of graphite and carbon black, carbon loading concentrations of $29.4 \mathrm{wt} \%$ with a graphite to carbon black ratio of 2.6 to 1 were able to achieve resistivities of $0.029 \Omega . \mathrm{cm}$, which is around five times lower than that achieved by carbon black alone [10]. Rheological characteristics of these carbon-black with graphite inks were intermediate between those of the solely carbon black or graphite inks in this study, with higher rest viscosities and mesh marking associated with greater proportions of carbon black relative to graphite.

A notable increase in filament formation occurring during ink separation in the screen-printing process was identified for all carbon morphologies at the optimum carbon loading, beyond which point, print quality and performance started to deteriorate. Relating to significant increases in surface roughness, the formation of print defects such as agglomerates, which resulted in no further significant improvements in conductivity with further increases in carbon concentration. When compared with the shear rheology profiles, there is an increase in elasticity with increase in carbon concentrations for all morphologies due to the increase in particle to particle interactions with concentration. Therefore, this filament formation may be due to the elastic response of the ink exceeding a particular threshold for that morphology. Increases in the elastic response of the ink corresponding to the formation of filamentation 
and resultant reductions in print quality were also observed by the authors in previous studies [26, 27]. In the study on the effects off snap off distance and print speed [27], increases in snap off distance led to increases in the separation rate between the mesh and substrate. This resulted in a greater elastic response and more filaments forming during separation. In the dilution study on a commercial carbon ink [26], the more elastic undiluted ink and $2.5 \mathrm{wt}$.\% dilution were found to form filaments during ink separation while the less elastic higher dilutions did not. This was a result of reductions in the interparticle distances, leading to fewer particle to particle and particle to polymer interactions that elastically store energy with greater dilutions. The dilution study also compared the locations of the filaments formed during separation with the print profile assessed with white light interferometry. It was found that the locations of these peaks corresponded with the filament separation locations, leading to increases in print roughness and reductions in print homogeneity. The presence of filamentation during printing was also found to significantly increase the print roughness and lead to print defects such as mesh marking in this study.

The interactions of the small carbon black particles had the most significant effect on the separation profiles out of the morphologies assessed. This led to significant filamentation during separation of the 20 wt $\%$ ink, which corresponded with significant mesh marking and higher volume resistivity than the other two dilutions, whereas the $15 \mathrm{wt} \%$ carbon black ink had no filaments form after the adhesion to extension stage during separation, resulting in a far lower surface roughness and better sheet resistivity. This also corresponds with the shear rheology tests, where carbon black leads to significant increases in the elasticity of the ink and at $20 \mathrm{wt} \%$ loading. In the dilution study, the commercial ink contained a combination of graphite and carbon black [26]. Based on these results, the dilution of the carbon black particles may have had a more significant impact on the separation profile than the graphite flakes, leading to the more significant filaments during separation and greater roughness in the print of the undiluted ink. This high-speed imaging of ink separation during screen-printing method combined with traditional shear rheology analyses could be used to optimise the concentration of other functional materials used in screen-printing inks. This would prevent the need for full printing trials, saving time and resources.

\section{Conclusions}

These studies have investigated how the concentration of different carbon morphologies can influence the shear rheological profile, the separating profile of an ink during printing and the resultant print profiles and conductivities of the prints. The carbon morphology had a significant effect on the packing of the particles. The smaller carbon black particles had more interactions leading to better electrical performance. There was an increase in the film thickness and print roughness with increases in carbon concentration for all morphologies, due to the increase in volume of interacting particles. Carbon concentration increases beyond $15 \mathrm{wt} \%$ for carbon black inks and $20 \mathrm{wt} \%$ for the graphite and GNP-based inks led to agglomerations of particles, mesh marking and increases in surface roughness. This prevented further improvements in the electrical performance of the print. These effects were most significant in the carbon black inks where the greater particle to particle interactions resulted in higher ink viscosities and elasticity. Visualisation of the print process with high speed imaging was able to identify an optimum carbon loading, beyond which filamentation resulted in print defects deleterious to conductivity. This is most evident in the carbon black-based inks, where there were significant amounts of filamentation during separation for the $20 \mathrm{wt} \%$ ink which lead to peaks and troughs in the print surface, resulting in mesh marking, high surface roughness and significant increases in sheet resistivity. Whereas for the $15 \mathrm{wt} \%$ ink, there was very little filamentation during ink separation, corresponding with significantly less surface roughness and print defects. Therefore, this high-speed imaging technique combined with traditional shear rheological analyses has provided a method for identifying the optimum particle concentration for a range of carbon morphologies. This technique could also be used to identify the optimum particle concentration of other functional materials used within screen-printing inks without the need for a full-scale print testing.

\section{Acknowledgements}

The authors would like to acknowledge the funding from the European Social Fund via the Welsh Government, the Engineering and Physical Sciences 
Research Council (Grant reference: EP/L015099/1) and icmPrint Ltd that has made this research possible. Parts of this work were conducted as a part of the P2CAR2 (Printing Process Control by Advanced Rheology 2) project, which was conducted as a project for the EPSRC Centre for Innovative Manufacture in Large-Area Electronics (CIMLAE). SEM facilities were provided by the Swansea University AIM Facility; funded in part by the EPSRC (EP/M028267/ 1), the European Regional Development Fund through the Welsh Government (80708) and the Ser Solar project via Welsh Government.

\section{Declarations}

Conflict of interest The authors declare that they have no conflict of interest.

Supplementary Information: The online version contains supplementary material available at http s://doi.org/10.1007/s10853-021-06724-1.

Open Access This article is licensed under a Creative Commons Attribution 4.0 International License, which permits use, sharing, adaptation, distribution and reproduction in any medium or format, as long as you give appropriate credit to the original author(s) and the source, provide a link to the Creative Commons licence, and indicate if changes were made. The images or other third party material in this article are included in the article's Creative Commons licence, unless indicated otherwise in a credit line to the material. If material is not included in the article's Creative Commons licence and your intended use is not permitted by statutory regulation or exceeds the permitted use, you will need to obtain permission directly from the copyright holder. To view a copy of this licence, visit http://creativecommons.org/licen ses/by $/ 4.0 /$.

Supplementary Information: The online version contains supplementary material available at http s://doi.org/10.1007/s10853-021-06724-1.

\section{References}

[1] Philip B, Jewell E, Greenwood P, Weirman C (2016) Material and process optimization screen printing carbon graphite pastes for mass production of heating elements.
J Manuf Process [Internet]. 22(1):185-191. https://doi.org/ 10.1016/j.jmapro.2016.03.001

[2] Park HK, Kim SM, Lee JS, Park JH, Hong YK, Hong CH et al (2015) Flexible plane heater: Graphite and carbon nanotube hybrid nanocomposite. Synth Met 203(1):127-134. https://doi.org/10.1016/j.synthmet.2015.02. 015

[3] Tehrani Z, Burwell G, Azmi MAM, Castaing A, Rickman R, Almarashi $J$ et al (2014) Generic epitaxial graphene biosensors for ultrasensitive detection of cancer risk biomarker. 2D Mater. 1(2):025004

[4] Tehrani Z, Korochkina T, Govindarajan S, Thomas DJ, Mahony JO, Kettle J et al (2015) Ultra-thin flexible screen printed rechargeable polymer battery for wearable electronic applications. Org Electron 26(1):386-394. https://doi.org/10. 1016/j.orgel.2015.08.007

[5] Baker J, Hooper K, Meroni S, Pockett A, McGettrick J, Wei $\mathrm{Z}$ et al (2017) High throughput fabrication of mesoporous carbon perovskite solar cells. J Mater Chem A 5(35):18643-18650

[6] Zhang L, Liu T, Liu L, Hu M, Yang Y, Mei A et al (2015) The effect of carbon counter electrodes on fully printable mesoscopic perovskite solar cells. J Mater Chem A 3(17):9165-9170

[7] Zabek D, Seunarine K, Spacie C, Bowen C (2017) graphene ink laminate structures on Poly(vinylidene difluoride) (PVDF) for pyroelectric thermal energy harvesting and waste heat recovery. ACS Appl Mater Interfaces 9(10):9161-9167

[8] Cao Z, Koukharenko E, Tudor MJ, Torah RN, Beeby SP (2016) Flexible screen printed thermoelectric generator with enhanced processes and materials. Sensors Actuators A Phys 238:196-206

[9] Sengupta R, Bhattacharya M, Bandyopadhyay S, Bhowmick AK (2011) A review on the mechanical and electrical properties of graphite and modified graphite reinforced polymer composites. Prog Polym Sci 36(5):638-670. http s://doi.org/10.1016/j.progpolymsci.2010.11.003

[10] Phillips C, Al-Ahmadi A, Potts S-J, Claypole T, Deganello D (2017) The effect of graphite and carbon black ratios on conductive ink performance. J Mater Sci. https://doi.org/10. 1007/s10853-017-1114-6

[11] He L, Tjong SC (2013) Low percolation threshold of graphene/polymer composites prepared by solvothermal reduction of graphene oxide in the polymer solution. Nanoscale Res Lett 8(1):2-8

[12] Wang C, Yi Y, Sastry AM, Shim J, Striebel KA (2004) Particle compression and conductivity in Li-Ion anodes with graphite additives. J Electrochem Soc 151(9):A1489-A1498

[13] Pantea D, Darmstadt H, Kaliaguine S, Roy C (2003) Electrical conductivity of conductive carbon blacks: influence of 
surface chemistry and topology. Appl Surf Sci 217(1):181-193

[14] Oxfall H, Ariu G, Gkourmpis T, Rychwalski RW, Rigdahl M (2015) Effect of carbon black on electrical and rheological properties of graphite nanoplatelets/poly(ethylene-butyl acrylate) composites. Express Polym Lett 9(1):66-76

[15] Erol M, Çelik E (2013) Graphite-Flake Carbon-Black-Reinforced Polystyrene-Matrix Composite Films Deposited on Glass-Fiber Woven Fabrics As Plane Heaters Kompozit Polistirena, Oja^an Z Grafitnimi Luskami in Sajami, Nanesen Na Tkanino Iz Steklenih Vlaken Za Plo[^Ate Grelnike. Mater Technol 47(1):25-28

[16] Azim SS, Satheesh A, Ramu KK, Ramu S, Venkatachari G (2006) Studies on graphite based conductive paint coatings. Prog Org Coatings 55(1):1-4

[17] Hatala M, Gemeiner P, Hvojnik M, Mikula M (2019) The effect of the ink composition on the performance of carbonbased conductive screen printing inks. J Mater Sci Mater Electron 30(2):1034-1044. https://doi.org/10.1007/s10854018-0372-7

[18] Phillips C, Al-Ahmadi A, Potts S-J, Claypole T, Deganello D (2017) The effect of graphite and carbon black ratios on conductive ink performance. J Mater Sci 52(16):9520-9530. https://doi.org/10.1007/s10853-017-1114-6

[19] Lei H, Pitt WG, McGrath LK, Ho CK (2004) Resistivity measurements of carbon-polymer composites in chemical sensors: Impact of carbon concentration and geometry. Sensors Actuators B Chem 101(1-2):122-132

[20] Lux F (1993) Models proposed to explain the electrical conductivity of mixtures made of conductive and insulating materials. J Mater Sci 28(2):285-301

[21] Zallen R (2005) Chapter 4. The percolation model. In: The physics of amorphous solids, pp 135-204. https://doi.org/10. 1002/3527602798.ch4

[22] Jewell EH, Hamblyn SM, Claypole TC, Gethin DT (2013) The impact of carbon content and mesh on the characteristics of screen printed conductive structures. Circuit World 39(1):13-21. https://doi.org/10.1108/03056121311298918

[23] Holder AJ, Claypole J, Claypole T, Cooper PG, Williams PR, Curtis DJ (2018) Fourier transform controlled stress parallel superposition (FT-CSPS): Validation and application in processing printable functional materials. Phys Fluids 30(7):077105. https://doi.org/10.1063/1.5029819

[24] Claypole A, Claypole J, Holder A, Claypole TC, Kilduff L (2020) Rheology of high-aspect-ratio nanocarbons dispersed in a low-viscosity fluid. J Coatings Technol Res. https://doi. org/10.1007/s11998-020-00319-2

[25] Xu C, Willenbacher N (2018) How rheological properties affect fine-line screen printing of pastes: a combined rheological and high-speed video imaging study. J Coatings Technol Res. https://doi.org/10.1007/s11998-018-0091-2

[26] Potts S-J, Phillips C, Claypole T, Jewell E (2020) The effect of carbon ink rheology on ink separation mechanisms in screen-printing. Coatings 10(10):1008

[27] Potts S-J, Phillips C, Jewell E, Clifford B, Lau YC, Claypole $\mathrm{T}$ (2020) High-speed imaging the effectof snap-off distance and squeegee speed on the ink transfer mechanism of screenprinted carbon pastes. J Coat Technol Res 17(2):447-459. h ttps://doi.org/10.1007/s11998-019-00291-6

[28] Matweb.com: TIMCAL TIMREX ${ }^{\circledR}$ SFG15 Primary Synthetic Graphite [Internet]. 2019 [cited 2019 Nov 15]. Available from: http://www.matweb.com/search/DataSheet.a spx?MatGUID=529537df1d0d429a9310acb1a070d96b

[29] Burton B (1971) A “creep yield stress" for superplastic deformation. Scr Metall 5(8):669-672

[30] Smits FM (1958) Measurement of sheet resistivities with the four-point probe. Bell Syst Tech J 37(3):711-718

[31] Barnes HA (2000) A handbook of elementary rheology. Vol. 6 , Polymer Composites. The University of Wales Institute of Non-Newtonian Fluid Mechanics, Department of Mathematics, University of Wales Aberystwyth. pp 1-210

[32] Kasgoz A, Akin D, Ayten AI, Durmus A (2014) Effect of different types of carbon fillers on mechanical and rheological properties of cyclic olefin copolymer (COC) composites. Compos Part B Eng 66:126-135

[33] Amari T, Uesugi K, Suzuki H (1997) Viscoelastic properties of carbon black suspension as a flocculated percolation system. Prog Org Coatings 31(1-2):171-178

Publisher's Note Springer Nature remains neutral with regard to jurisdictional claims in published maps and institutional affiliations. 